\title{
Maternal-foetal glucose kinetics in conscious, catheterised sheep
}

\section{By J. C. Hodgson and D. J. Mellor, Moredun Research Institute, Gilmerton, Edinburgh EH1 $77 \mathfrak{F H}$}

Estimates of the foetal uptake of glucose from maternal plasma have been obtained by comparing glucose utilization rates in non-pregnant and pregnant sheep (Bergman, 1964) and by measuring umbilical blood flow and venous-arterial glucose concentration differences (James, Raye, Gresham, Makowski, Meschia \& Battaglia, 1972; Boyd, Morriss, Meschia, Makowski \& Battaglia, 1973). These estimates of the maternal contribution to the foetal glucose requirement can give no information about the extent of foetal gluconeogenesis, which may provide a significant amount of foetal glucose since about $50 \%$ of foetal oxygen consumption can be accounted for by catabolism of amino acids and lactate (Gresham, James, Raye, Battaglie, Makowski \& Meschia, 1972; Burd, Jones, Simmons, Makowski, Meschia \& Battaglia, 1975). Irreversible loss of glucose from foetal blood provides a direct estimate of the foetal glucose requirement and can be obtained only with radio-isotope techniques. The accurate estimate requires direct access to the foetal vasculature, which is now possible with the advent of foetal chronic catheterisation techniques (Meschia, Cotter, Breathnach \& Barron, 1965).

Radio-isotopes can be given as a single shot or by continuous infusion. Multicompartmental analysis of single-shot data provides information on the structure of the system in terms of the number and size of individual pools and the rates of transfer between pools. The precision of the model may be checked and improved by reference to results obtained in continuous infusion experiments, which provide independent estimates of some of the model values.

A three-compartment model, describing glucose metabolism in non-pregnant sheep, has been proposed by White, Steel, Leng \& Luick ( 1969 ) since third-order exponential equations provided the best fit to the specific activity $v$. time curves in single-shot experiments. From this work it may be anticipated that a model relating to the pregnant sheep would probably have four or more compartments. However, although glucose specific activity $v$. time curves obtained in pregnant sheep are distinctly more curvilinear than those obtained in non-pregnant sheep (White et al. 1969), no more than three exponential terms have been resolved (Steel \& Leng, 1973). Further terms may be resolved if the specific activity $v$. time curves were more accurately defined, particularly at the point of inflexion, by taking large numbers of samples or using large amounts of tracer or both. Alternatively it is possible that evidence for extra compartments cannot be $36(1) 3$ 
obtained on the basis of maternal results alone, and that a complete model describing the glucose kinetics in mother and foetus must include findings from the foetus.

In this laboratory we have successfully sampled maternal and foetal blood during continuous infusion or after single-shot administration of differently labelled glucose tracers into the maternal or foetal circulations or both, and we have thus been able to base the mathematical analysis on data from both mother and foetus. We have infused five sheep on up to six occasions (total of eighteen) and have used the single-shot approach once or twice in nine sheep (total of sixteen). While more information is derivable from single-shot experiments, continuous infusion has several practical advantages. Fewer and smaller samples of blood are required from the foetus so that more infusion than single-shot experiments can be performed on the same foetus before its circulation becomes compromised by blood loss, infusion experiments can be conducted at earlier foetal ages and on foetuses in which sampling of blood through catheters is difficult, and the analytical burden is reduced. Finally, infusions are less time-consuming.

Both approaches rest on the fundamental assumption that the mother and foetus are in a metabolic steady state with respect to glucose. Although in principle a steady state cannot be achieved in the pregnant animal near term because of the rapidity of foetal growth, we consider that the likely maximum increase of about $10 \%$ in the foetal glucose requirement (derived from foetal weight findings in Barcroft, 1946) that could occur during the $30 \mathrm{~h}$ required to perform two infusions or one 'single-shot' experiment is low enough to be disregarded. Accordingly the experimental conditions were chosen in order to establish and maintain constant plasma glucose concentrations. We are aware that a constant glucose concentration does not necessarily reflect the presence of steady state glucose entry rates or irreversible losses from the blood, but at present this is the only index available. (I) The animals were handled daily for at least 7 weeks after being brought into the laboratory, because up to 6 weeks of such treatment is required before pregnant sheep brought in from the field cease to be disturbed by experimental procedures requiring prolonged and direct contact with the experimenter (Pearson \& Mellor, 1976). (2) Tracer experiments were not performed until the effects of umbilical catheterisation (Mellor \& Matheson, 1975) had disappeared. We have found that this takes up to $14 \mathrm{~d}$ in fully trained sheep (Pearson \& Mellor, 1975; Mellor, Matheson, Small \& Wright, 1976; Slater \& Mellor, 1977). (3) In order to avoid the marked changes in plasma glucose concentrations observed in sheep fed once daily (Table $\mathrm{I}$ ), the daily ration was provided in twenty-four equal portions at hourly intervals. Plateau glucose concentrations were achieved in mother and foetus 5 to $7 \mathrm{~d}$ after the introduction of hourly feeding, and the animals were fed hourly for a minimum of $10 \mathrm{~d}$ before experiments began. (4) The temperature range in the laboratory was standardized at $10-14^{\circ}$ in order to avoid effects of ambient temperature on the plasma glucose concentrations of pregnant sheep (Mellor, Slater \& Matheson, 1975). This facilitated comparison of results obtained in different experiments and within individual experiments. 
Table I. Plasma glucose concentrations ( $\mathrm{mg} / \mathrm{L}$ ) in ewes fed once daily or at hourly intervals

(Each value represents the mean ( $\pm \mathrm{SE}$ ) plasma glucose concentration of six sheep)

\begin{tabular}{lccccccc} 
& \multicolumn{7}{c}{ Time (hours) } \\
& 09.00 & 13.00 & 17.00 & 21.00 & 01.00 & 05.00 & 09.00 \\
Once daily & $405 \pm 21$ & $500 \pm 27$ & $633 \pm 30$ & $612 \pm 35$ & $532 \pm 28$ & $500 \pm 21$ & $450 \pm 24$ \\
Hourly & $681 \pm 5$ & $678 \pm 15$ & $710 \pm 8$ & $691 \pm 10$ & $684 \pm 10$ & $704 \pm 13$ & $703 \pm 7$
\end{tabular}

-Mellor \& Slater (unpublished results related to Mellor \& Slater, 1973).

It should be noted that any steady state established by the above conditions may be disturbed within $7 \mathrm{~d}$ of birth by the marked hormone changes taking place in mother and foetus during this period (see Challis \& Thorburn, 1975), though at present the combined effects of these hormone changes on glucose metabolism are unknown. In addition, the combined effects of the experimental procedures may alter the course of pregnancy. For instance, in four of the fourteen sheep used in these studies birth occurred $\mathrm{I}$ to $5 \mathrm{~d}$ before the normal period of pregnancy for Scottish Blackface sheep in this laboratory (144-151 d).

The animals were maintained on the dietary regimen described by Mellor $e t a l$. (1975), which was designed to maintain body-weight constant throughout pregnancy. This level of nutrition was equivalent to the best conditions likely to be encountered on hill farms (Russell, Gunn \& Doney, 1968). Animals fed once daily or hourly at the above levels have pre-feeding jugular plasma glucose concentrations of $500-55^{\circ}$ and $650-700 \mathrm{mg} / \mathrm{l}$, respectively, at $10-14^{\circ}$. The corresponding glucose concentrations in umbilical arterial plasma are $130-170$ and $150-200 \mathrm{mg} / \mathrm{l}$, respectively.

The glucose tracers used in these experiments were $\left[\mathrm{U}-{ }^{14} \mathrm{C}\right]$ and $\left[2-{ }^{3} \mathrm{H}\right] \mathrm{glucose}$. $\left[\mathrm{U}-{ }^{14} \mathrm{C}\right.$ ]glucose has been the tracer most commonly employed in studies of glucose kinetics and it is now accepted that its use yields estimates of the rate of irreversible loss of glucose (see Leng, 1970). Katz \& Dunn (1967) compared glucose kinetic results using $\left[2-{ }^{3} \mathrm{H}\right]$ and $\left[\mathrm{U}-{ }^{14} \mathrm{C}\right.$ glucose in the rat and found that the entry rate of glucose was higher when estimated from the $\left[2-{ }^{3} \mathrm{H}\right]$ glucose results. Similar findings were reported for the sheep (Judson \& Leng, 1972). These results were interpreted as meaning that $\left[2-{ }^{3} \mathrm{H}\right]$ glucose was not recycled to the glucose pool and was thus providing an estimate of the total entry rate of glucose. However, it should be noted that total entry rate may be underestimated in sheep if activity present in glucose intermediates appears in recycled glucose (Van der Walt, 1975).

In single-shot experiments $\left[\mathrm{U}-{ }^{14} \mathrm{C}\right]$ and $\left[2-{ }^{3} \mathrm{H}\right]$ glucose were injected simultaneously into the foetus and the ewe, respectively. In each continuous infusion experiment both tracers were again given simultaneously, but on the first day into the foetus only and the next day into the mother. The tracers were administered via the foetal umbilical vein and a maternal jugular vein and blood samples were withdrawn from the foetal umbilical artery and the other maternal jugular vein. 
The presence of fructose in foetal plasma interferes with the determination of the specific activity of glucose when isolated as the pentaacetate derivative (see Jones, 1965). Therefore an alternative method of measuring glucose specific activity was devised which involved the deionization of the protein-free plasma filtrates, freeze-drying, conversion of the glucose to gluconic acid and the separation of the acid from fructose using anion exchange columns.

The single-shot results were processed using the SAAM 25 computer program (Berman \& Weiss, 1971) and the continuous infusion results by the method of Shipley \& Clark (1972). No attempt was made during the present continuous infusion experiments to describe the build-up of the plasma glucose specific activity to plateau as the calculation of pool sizes, total entry rates and recycling rates from these results may be subject to large error (see Nolan \& Leng, 1974). Instead estimates of the total entry rate and recycling rate, in addition to the rate of irreversible loss of glucose, were obtained by using combinations of the two tracers as described above. As yet the analysis of results from all of the experiments is incomplete. We have therefore presented preliminary results from one single-shot experiment in one sheep carrying a single foetus and from two infusion experiments in sheep carrying twins, as an illustration of the information that can be obtained and of some of the problems attached to this type of experiment.

To model the maternal-foetal glucose kinetics it is necessary to be able to subject the results from mother and foetus simultaneously to the mathematical analysis. So far this has not been possible due to technical difficulties with the SAAM 25 program. However, from the limited modelling which has been performed, several important observations can be made. It has been assumed in the modelling that as neither $\left[2-{ }^{3} \mathrm{H}\right]-$ nor $\left[\mathrm{U}-{ }^{14} \mathrm{C}\right]$ glucose was recycled to any extent in the mother (cf. continuous infusion results), the model for the mother derived from ${ }^{3} \mathrm{H}$ results would be similar to one derived from ${ }^{14} \mathrm{C}$ results.

The results from the single-shot experiment were subjected to both multiexponential and multicompartmental analysis. We found that in both mother and foetus the specific activity $v$. time curves could be described by equations containing three exponential terms, which in the foetus was consistent with a three-compartment model. However, in the mother, for the model to be compatible with the data, four compartments were necessary. This is not likely to be due to any biological variation and most probably reflects the degree of error in the experimental results. These preliminary models are presented in Fig. 1 ; the model for the mother is taken from Horsfield, Infield \& Annison (1974) and for the foetus from Kronfeld, Ramberg \& Shames (197I). The notation used is that of Shipley \& Clark (1972).

Pool $a$ of the maternal model included the sampled compartment (plasma) and together with pool $b$ probably included extracellular glucose. The 'space' occupied by glucose in pools $a$ and $b$ was $24 \%$ of the body-weight, slightly higher than the mean value of $20 \%$ reported by Holmes \& English (1969) for the extracellular volume in sheep. Pool $c$ may include metabolites of glucose, some of which are 

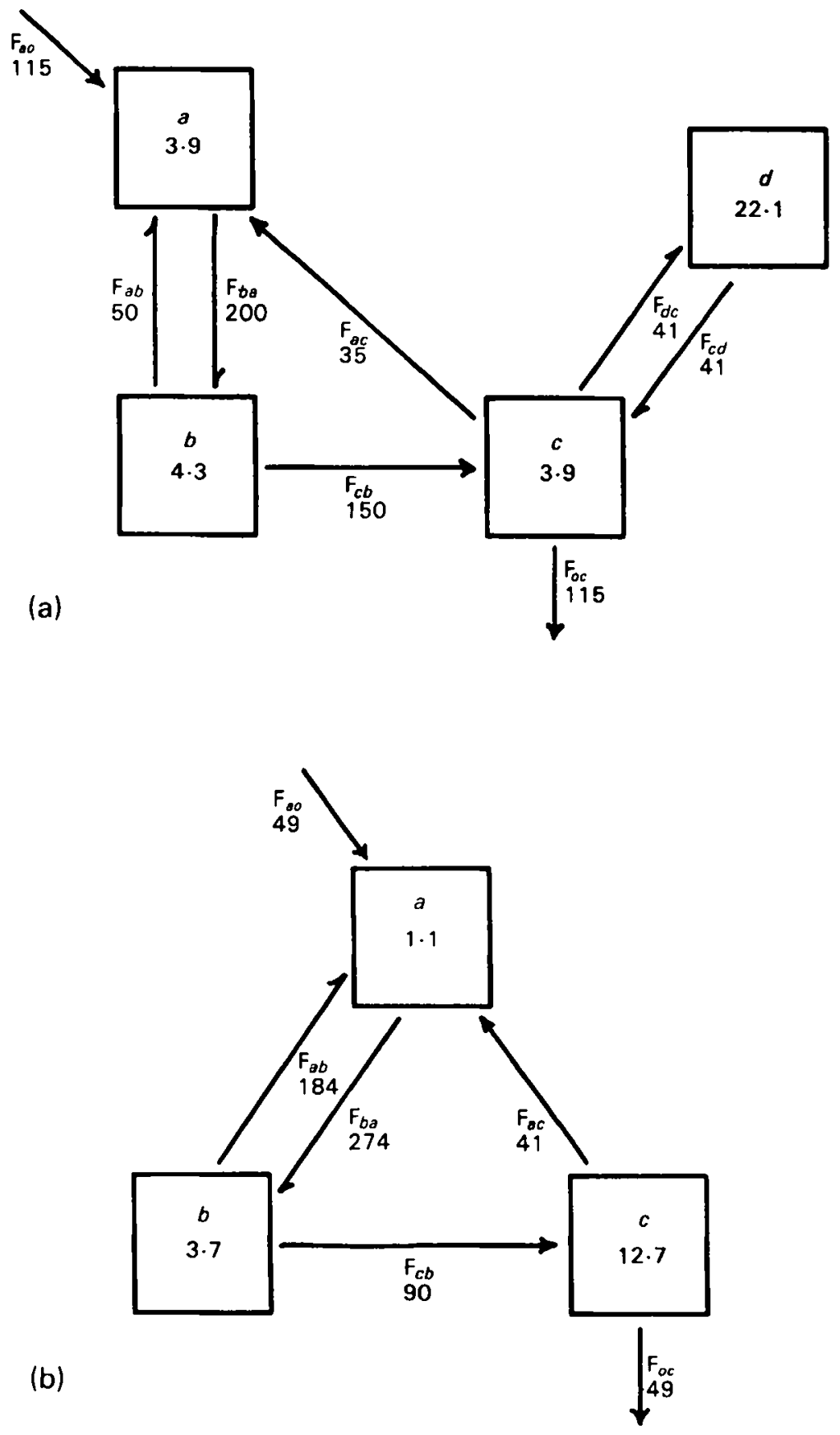

Fig. I. Preliminary models derived from results of single-shot radio-isotope experiments, describing the kinetics of glucose metabolism in (a) the mother and in (b) the foetus. Flow rates (F) are in $\mathrm{g}$ glucose $/ 24 \mathrm{~h}$, pool sizes are in $\mathrm{g}$ glucose. For details of pools see p. $3^{6}$. 
returned to the sampled pool. Similar considerations may apply to the foetus. The total entry rate of glucose into the sampled compartment is equivalent to $F_{b a}$ in both models and is higher in the foetus than in the mother, indicating a higher rate of glucose metabolism in the foetus. Recycling of glucose, represented by fows $\mathrm{F}_{a b}$ and $\mathrm{F}_{a c}$ is higher in the foetus than in the mother, the difference being almost entirely due to the higher rate of return of glucose from pool $b$ to pool $a$. Recycling rates in non-pregnant and pregnant sheep, equivalent to $3-76$ and $10-42 \mathrm{~g} / 24 \mathrm{~h}$, respectively, have been reported (White et al. 1969; Steel \& Leng, 1973). The rate of irreversible loss $\left(\mathrm{F}_{o c}\right)$ is equivalent to the rate of input of 'fresh' glucose to the samples pool $\left(\mathrm{F}_{a o}\right)$, i.e., the glucose production rate. However, from these 'independent' maternal and foetal models it is not possible either to estimate the rate of foetal gluconeogenesis, or, if gluconeogenesis is significant, to differentiate between maternal and foetal contributions to glucose production rates. Also the value for maternal irreversible loss will underestimate the combined irreversible losses from the maternal and foetal circulations if any glucose irreversibly lost from the foetus has not passed through the maternal pool, which would be the case if foetal gluconeogenesis is significant. It is possible to assess the proportion of foetal irreversible loss in the term for maternal irreversible loss in Fig. I, and vice versa, by reference to the areas under the specific activity $v$. time curves in both the maternal and foetal circulations when either mother or foetus is infused. From these results, 'corrected' values for the irreversible loss of glucose from the mother and foetus of 52 and $44 \mathrm{~g} / 24 \mathrm{~h}$, respectively can be calculated

The treatment of the continuous infusion results is based on the concept that entry rates are estimated from ${ }^{3} \mathrm{H}$ values, and production rates from ${ }^{14} \mathrm{C}$ values. It is implicit in this concept that production rates can be equal to, but not greater than, the entry rates. The model used in the calculation of kinetic parameters from continuous infusion data and the values obtained are presented in Fig. 2 and Table 2, respectively. It can be seen that generally the rates estimated from ${ }^{14} \mathrm{C}$ values are either approximately equal to or less than those estimated from ${ }^{3} \mathrm{H}$ values. On the occasions when substantial deviations from this concept were

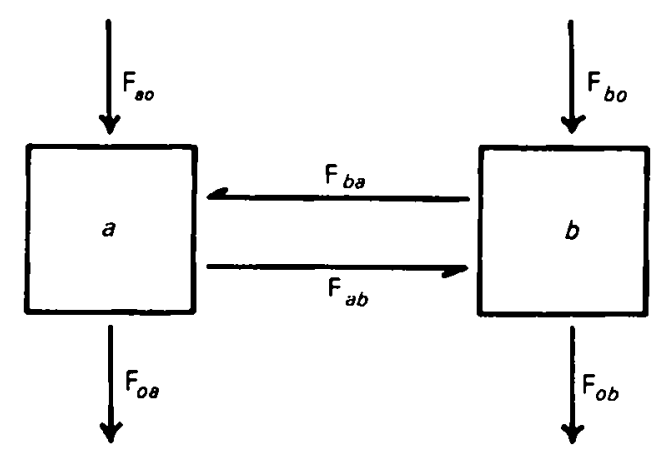

Fig. 2. Model used in the calculation of glucose kinetic parameters from continuous infusion results. For details see above. 
Table 2. The rates of flow of glucose through the pools of the continuous infusion model using two glucose labels

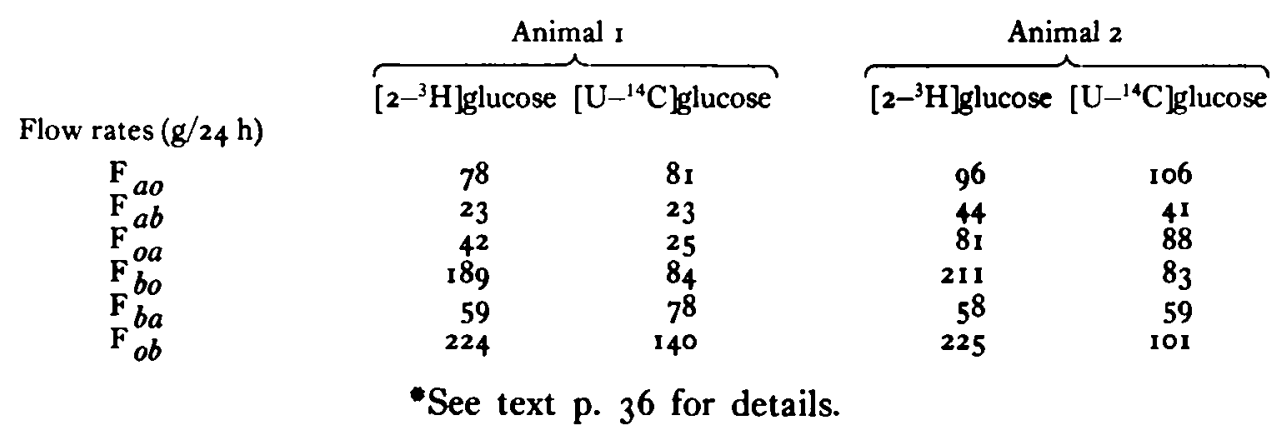

observed, we attributed the differences to experimental error. Where this was apparent, the values calculated from ${ }^{3} \mathrm{H}$ results were taken to represent the 'true' flux. The interpretation of the results is complicated by the existence of a second foetus, which influences the calculation of the maternal kinetic parameters by an amount which can be estimated only if the second foetus is infused. The major effect is to over-estimate the maternal rate of glucose production $\left(\mathrm{F}_{a o}\right)$ and of irreversible loss $\left(\mathrm{F}_{o a}\right)$. Foetal data, however, refer specifically to the sampled foetus and can be interpreted accordingly.

Data on the net placental transfer of glucose from mother to foetus, obtained from the difference between the flow rates $F_{b a}$ and $F_{a b}$, showed that this parameter was the one most affected by experimental error. For animal I the rate was $3^{6}$ or $55 \mathrm{~g} / 24 \mathrm{~h}$ and for animal 2 , 14 or $18 \mathrm{~g} / 24 \mathrm{~h}$ for ${ }^{3} \mathrm{H}$ or ${ }^{14} \mathrm{C}$ data, respectively. These values compare with values which can be calculated from the literature of $45 \mathrm{~g} / 24 \mathrm{~h}$ (Bergman, 1964), 42-1 $20 \mathrm{~g} / 24 \mathrm{~h}$ (Setchell, Bassett, Hinks \& Graham, 1972) and $26 \mathrm{~g} / 24 \mathrm{~h}$ (Boyd et al. 1973). The ratio of foetal to maternal glucose specific activity when the mother was infused indicated that maternal glucose-carbon supplied 48 and $4 \mathrm{r} \%\left({ }^{14} \mathrm{C}\right.$ data) of the 'fresh' glucose-carbon and that maternal glucose molecules supplied 24 and $22 \%\left({ }^{3} \mathrm{H}\right.$ data) of the total glucose-carbon entering the two sampled foetal circulations.

There was no evidence of maternal recycling of glucose in either animal as the value for the entry rate of glucose $\left(\mathrm{F}_{a o},{ }^{3} \mathrm{H}\right.$ data) were similar to the production rates $\left(\mathrm{F}_{a o},{ }^{14} \mathrm{C}\right.$ data). However, in the sampled foetuses, glucose entry rates $\left(\mathrm{F}_{b o n}{ }^{3} \mathrm{H}\right.$ data) were markedly higher than production rates $\left(\mathrm{F}_{b o},{ }^{14} \mathrm{C}\right.$ data), indicating considerable recycling. Both of these observations support the data obtained in the single-shot experiment.

The rates of foetal irreversible loss of glucose $\left(\mathrm{F}_{o b},{ }^{14} \mathrm{C}\right.$ data $)$ were considerably higher than the net rates of placental transfer. The discrepancy cannot be attributed to foetal glycogenolysis as this would have supplied a total of only $3 \mathrm{I}-45 \mathrm{~g}$ of glucose, assuming the mobilization of the entire glycogen reserves of each foetus during the experiment (derived for foetal weights of 2.3 and $3.4 \mathrm{~kg}$, from Barcroft (1946) and Shelley ( 1960$)$ ), which is unlikely in foetuses in a metabolic 
steady state. This is further confirmed by the observation that plateau specific activities were achieved in both experiments. Thus, either glycogen turnover was sufficiently rapid that equilibration with glucose tracer was complete, in which case glycogenolysis will be included in the rate of recycling, or glycogen was acting as a sink returning unlabelled glucose to the sampled pool at a rate that was insignificant when compared with the production rate. Accordingly, if the foetal irreversible loss is taken as the measure of the requirement for glucose, 60 and $82 \%$ of this requirement was met by foetal gluconeogenesis. This is the first demonstration that substantial amounts of the metabolites used as energy sources by the foetus first pass through the glucose pool.

\section{REFERENCES}

Barcroft, J. (1946). Researches on Pre-natal Life. Oxford: Blackwell Scientific Publications. Bergman, E. N. (1964). Nature, Lond. 202, 1333.

Berman, M. \& Weiss, M. F. (197I). SAAM Manual, USPHS Publication No. 1703. Washington, DC: US Government Printing Office.

Boyd, R. D. R., Morriss, F. H. Jr., Meschia, G., Makowski, E. L. \& Battaglia, F. C. (1973). Am. J. Physiol. 225, 897 .

Burd, L. I., Jones, M. D. Jr., Simmons, M. A., Makowski, E. L., Meschia, G. \& Battaglia, F. C. (1975). Nature, Lond. 254, 7 I0.

Challis, J. R. G. \& Thorburn, G. D. (1975). Br. med. Bull. 31, 57.

Gresham, E. L., James, E. J., Raye, J. R., Battaglia, F. C., Makowski, E. L. \& Meschia, G. (1972). Pediatrics 50, 372.

Holmes, E. M. \& English, P. B. (1969). Res. vet. Sci. 10, 73.

Horsfield, S., Infield, J. M. \& Annison, E. F. (1974). Proc. Nutr. Soc. 33, 9.

James, E. J., Raye, J. R., Gresham, E. L., Makowski, E. L., Meschia, G. \& Battaglia, F. C. (1972). Pediatrics 50, 361.

Jones, G. B. (1965). Analyt. Biochem. 12, 249.

Judson, G. J. \& Leng, R. A. (1972). Aust. F. biol. Sci. 25, 1313.

Katz, J. \& Dunn, A. (1967). Biochemistry 6, 1.

Kronfield, D. S., Ramberg, C. F. Jr. \& Shames, D. M. (1971). Am. F. Physiol. $220,886$.

Leng, R. A. (1970). Adv. vet. Sci. 14, 209.

Mellor, D. J. \& Matheson, I. C. (1975). Res. vet. Sci. 18, 221.

Mellor, D. J., Matheson, I. C., Small, J. \& Wright, H. (1976). Res. vet. Sci. 2 I, 102.

Mellor, D. J. \& Slater, J. S. (1973). F. Physiol., Lond. 234, 519.

Mellor, D. J., Slater, J. S. \& Matheson, I. C. (1975). Res. vet. Sci. 18, 219.

Meschia, G., Cotter, J. R., Breathnach, C. S. \& Barron, D. H. (1965). Q. Fl exp. Physiol. 50, I85.

Nolan, J. V. \& Leng, R. A. (1974). Proc. Nutr. Soc. 33, I.

Pearson, R. A. \& Mellor, D. J. (1975). Res. vet. Sci. 19, 102.

Pearson, R. A. \& Mellor, D. J. (1976). Res. vet. Sci. 20, 215.

Russell, A. J. F., Gunn, R. G. \& Doney, J. M. (1968). Anim. Prod. 10, 43.

Setchell, B. P., Bassett, J. M., Hinks, N. T. \& Graham, N. McC. (1972). Q. Fl exp. Physiol. 57, 257.

Shelley, H. J. (1960). J. Physiol., Lond. $153,527$.

Shipley, R. A. \& Clark, R. E. (1972). Tracer Methods for in vivo kinetics. Theory and Applications. New York and London: Academic Press.

Slater, J. S. \& Mellor, D. J. (1977). Res. vet. Sci. 22, 95.

Steel, J. W. \& Leng, R. A. (1973). Br. F. Nutr. 30, 45 I.

Van Der Walt, J. G. (1 975 ). Onderstepoort F. vet. Res. 42, 63 .

White, R. G., Steel, J. W., Leng, R. A. \& Luick, J. R. (1969). Biochem. J. 1 14, 203. 